\title{
molecules
}

ISSN 1420-3049

Article

www.mdpi.com/journal/molecules

\section{Synthetic Organic Electrochemistry in Ionic Liquids: The Viscosity Question}

\author{
Steven Bornemann ${ }^{1}$ and Scott T. Handy ${ }^{2, *}$ \\ 1 Department of Chemistry, Binghamton University, Binghamton, NY 13902, USA \\ 2 Department of Chemistry, Middle Tennessee State University, Murfreesboro, TN 37132, USA \\ * Author to whom correspondence should be addressed; E-Mail: shandy@mtsu.edu; \\ Tel.: +1-615-904-8114; Fax: +1-615-898-5182.
}

Received: 1 June 2011; in revised form: 17 June 2011 / Accepted: 27 June 2011 /

Published: 18 July 2011

\begin{abstract}
Ionic liquids are obvious candidates for use in electrochemical applications due to their ionic character. Nevertheless, relatively little has been done to explore their application in electrosynthesis. We have studied the Shono oxidation of arylamines and carbamates using ionic liquids as recyclable solvents and have noted that the viscosity of the medium is a major problem, although with the addition of sufficient co-solvent, good results and excellent recovery and recycling of the ionic liquid can be achieved.
\end{abstract}

Keywords: room temperature ionic liquid; carbamate oxidation; constant current; viscosity; organic electrosynthesis

\section{Introduction}

One of the universal truths regarding electrochemistry is that the reaction medium must be capable of carrying a charge. In general this has been accomplished by employing a supporting electrolyte (a salt) that is soluble in the reaction medium. While highly successful, this does limit the "greenness" of electrochemistry by necessitating a separation event and creating a waste material. Further, the supporting electrolyte is often one of the most expensive materials used in synthetic electrosynthesis. As a result, it would be of great potential benefit if the supporting electrolyte could be both readily separable from the reaction products and also readily recycled.

In recent years, the advent of hydrolytically stable room temperature ionic liquids (RTILs) has provided new and unusual solvents for reactions [1-3]. RTILs can be simply characterized as salts that 
are liquid at or below room temperature. Thus they are comprised of a cation (usually a relatively large organic cation) and an anion (usually a weakly coordinating inorganic anion), several examples of which can be seen in Figure 1. They have attracted increasing attention as potential green solvents over the last several years since they are, for all practical purposes nonvolatile and thus readily recyclable [4]. Additionally, they appear to be favorable media for a wide range of organometallic reactions and are often capable of providing extra stabilization to catalysts, thereby rendering them recyclable as well $[5,6]$. We have been interested in the use of RTILs in organic synthesis as well as the preparation of new RTILs [7-12]. During the course of these efforts, we have also been struck by the fact that, as salts, RTILs should provide a good, conducting medium in which to perform electrosynthesis. We have not been alone in this observation, as there have been a few other reports of the use of RTILs in organic electrosynthesis $[13,14]$. Surprisingly, though, this activity has been largely limited to a few select areas of organic electrosynthesis: polymerizations [15-17], fluorinations [18-23], oxidations [24-28], reductions [29,30], transition-metal catalyzed couplings/dehalogenations [31-35], and electrogenerated bases [36-40]. In this paper, we wish to outline our results on Shono-type carbamate oxidations as well as some observations regarding the impact that solvent viscosity has on the outcome of these (and possibly other) reactions.

Figure 1. Representative ionic liquid components.

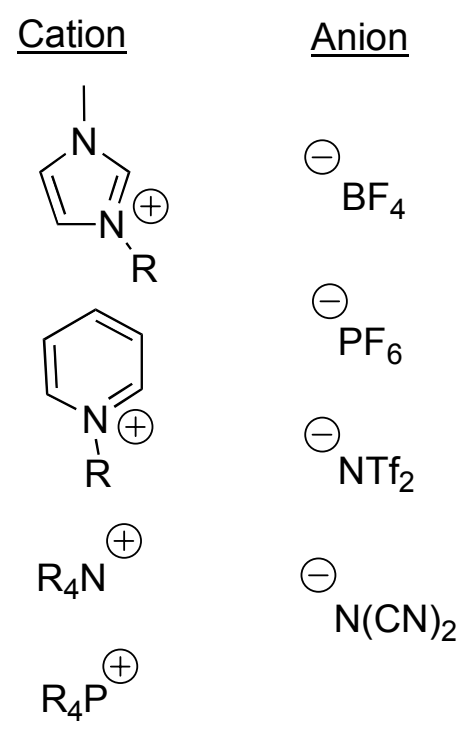

\section{Results and Discussion}

The Shono-type oxidation of carbamates is certainly one of the simpler and yet more versatile electrochemical transformations [41]. It has been performed on a wide range of carbamate, amide, and even aniline substrates to afford either alkoxylated or alkene products. Both of these products can in turn be further transformed into a wide range of new products and have found a number of applications in natural and non-natural products synthesis. The simplicity of the reaction stems from the fact that it is performed under constant current conditions, meaning that the apparatus and set-up for the reaction is quite simple. Armed with a basic power supply, initial attempts were made to transform carbamate $\mathbf{1}$ into methoxylated product 2 using tributyldecylammonium tosylate as the solvent along with 5 equivalents (5 volume \%) of methanol (Scheme 1). Under these conditions, the reaction mixture 
rapidly darkened and carbamate 1 was not consumed until over $3.5 \mathrm{~F} / \mathrm{mol}$ of current was passed. Ultimately, traces of the desired product $\mathbf{2}$ could be isolated as well as some dimethoxylated product $\mathbf{3}$. The RTIL itself was a black, syrupy mixture that contained numerous impurities based on ${ }^{1} \mathrm{H}$ NMR analysis of the recovered RTIL.

Scheme 1. Shono oxidation in tributyldecylammonium tosylate.

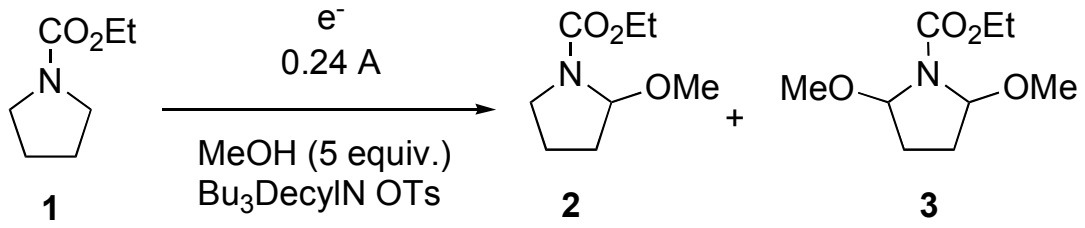

The darkening of the RTIL was unexpected given its wide electrochemical window (as determined by CV). Indeed, the CV's of all three RTILs employed in this study displayed little reactivity between -2.8 and $3.2 \mathrm{~V}$. Representative CV's of tributyldecylammonium tosylate and the corresponding triflimide can be found in Figure 2.

Figure 2. Electrochemical windows of the tributyldecylammonium RTILs.

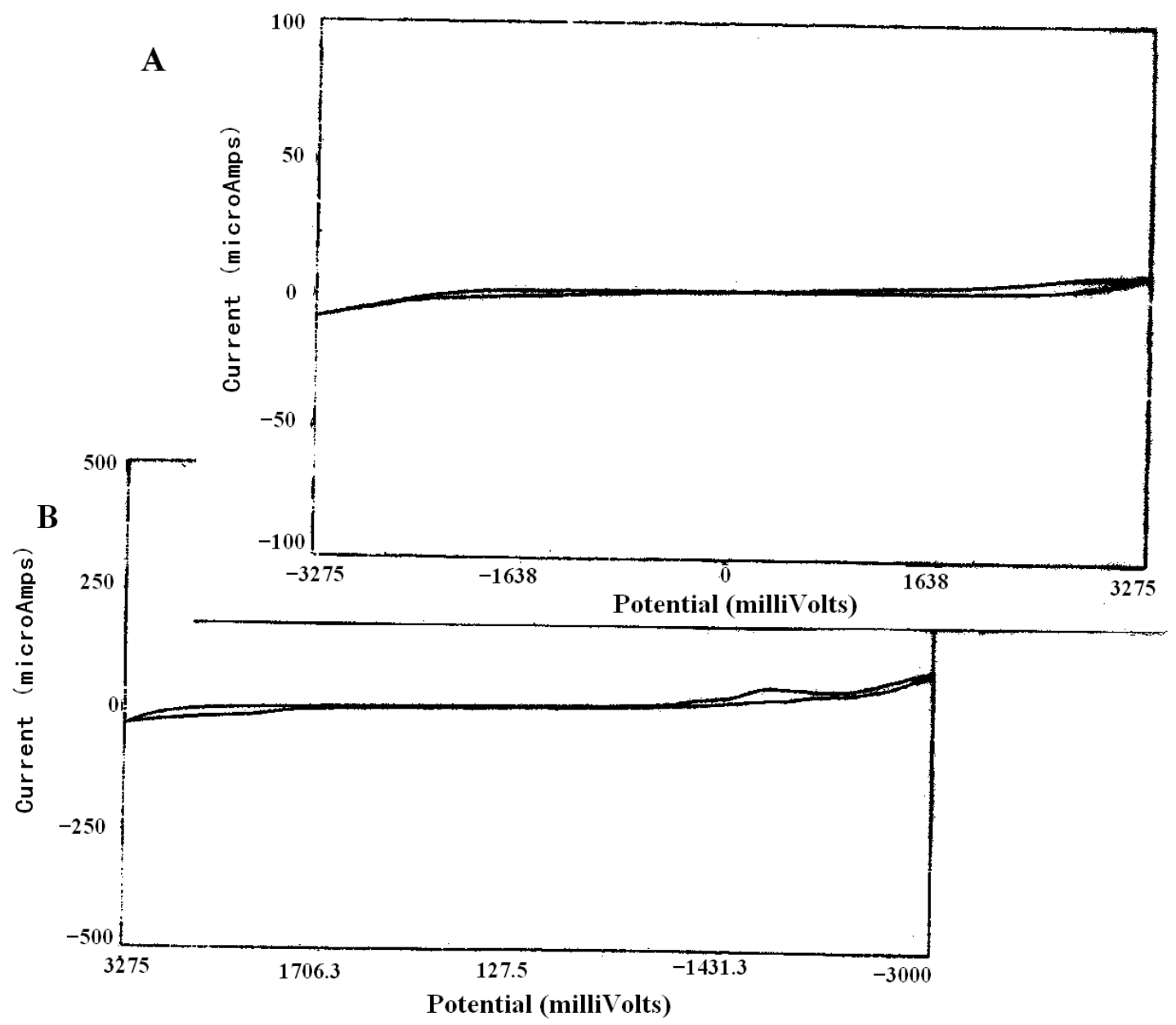

A: CV of Tributyldecylammonium tosylate; B: CV of Tributyldecylammonium triflimide. 
This initial result was not terribly promising, since the RTIL could not be recycled. Interestingly, though, by increasing the volume $\%$ of methanol, better results could be obtained (Table 1). Although a volume $\%$ of 33 still resulted in darkened RTIL that could not be recycled, increasing this further to an equivolume mixture of ionic liquid and methanol finally resulted in a good yield of oxidation product 2 after passing $2.5 \mathrm{~F} / \mathrm{mol}$ of current. Further, the ionic liquid was pale yellow and readily recovered at the end of the reaction. Further increasing the percentage of methanol resulted in minor improvements in terms of yield and the physical state of the recovered ionic liquid.

Table 1. Effect of increasing volume\% of methanol on the oxidation of carbamate $\mathbf{1}$ in tributyldecylammonium tosylate.

\begin{tabular}{ccccc}
\hline Entry & Volume\% MeOH & \% Yield of 2 & State of RTIL & Viscosity (cP) \\
\hline 1 & 33 & 0 & Dark black & 120 \\
2 & 50 & 88 & Pale yellow & 15 \\
3 & 67 & 90 & Clear & 7 \\
\hline
\end{tabular}

At this point, it was clear that the use of tributyldecylammonium tosylate as the ionic liquid solvent was not going to prove satisfactory. As will be discussed further, it was suspected that the viscosity of the medium might be playing a role in the observed results, so we opted for a less viscous ionic liquid - Tributyldecylammonium triflimide. Using this much less viscous ionic liquid, low volume\%'s of methanol still resulted in significant darkening (decomposition) of the ionic liquid and low yields of the desired oxidation product 2 (Table 2). However, by the time the volume \% reached 33, a pale yellow reaction mixture resulted from which $89 \%$ of 2 could be isolated and the RTIL recycled in further reactions (Table 2, entry 3). Thus, after passing $2.2 \mathrm{~F} / \mathrm{mol}$ of current, the methanol was removed via evaporation and the product and any remaining starting material were then removed by extraction with diethyl ether. After chromatography, product 2 was isolated in $89 \%$ yield, along with $8 \%$ of the starting carbamate 1 . The resulting RTIL layer was pale yellow and could be reused in further reactions after drying in vacuo at $5{ }^{\circ} \mathrm{C}$ overnight (Table 2, entries 5-7). Increasing the volume \% of methanol further did not result in any additional benefit (Table 2, entry 4).

Table 2. Oxidation of carbamate 1 in tributyldecylammonium triflimide.

\begin{tabular}{ccccc}
\hline Entry & Volume\% MeOH & \% Yield of 2 & State of RTIL & Viscosity (cP) \\
\hline 1 & 10 & 10 & Black & 150 \\
2 & 20 & 45 & Dark brown & 50 \\
3 & 33 & 89 & Pale yellow & 10 \\
4 & 50 & 93 & Clear & 5 \\
$5^{\text {a }}$ & 33 & 89 & Pale yellow & \\
$6^{\mathrm{b}}$ & 33 & 91 & Pale yellow & \\
$7^{\text {c }}$ & 33 & 93 & Pale yellow & \\
\hline
\end{tabular}

${ }^{\mathrm{a}}$ RTIL recycled from entry $3 ;{ }^{\mathrm{b}}$ RTIL recycled from entry $5 ;{ }^{\mathrm{c}}$ RTIL recycled from entry 6 .

Although successful, we were still unsatisfied with the amount of methanol that was required for these reactions. In an effort to further minimize the amount of methanol employed, we sought an even less viscous RTIL that was still readily available and electrochemically stable. To this end, 
1-ethyl-3-methylimidazolium triflimide was selected. (Table 3) Gratifyingly, the volume \% of methanol required for clean reaction did decrease to $25 \%$. Under these conditions, good conversion to product 2 was observed and the RTIL could be readily recycled after drying in vacuo overnight.

Using these same conditions, a number of carbamates could be oxidized in similar fashion and in good yield (Table 4). Isolation of the products and recycling of the RTIL was straightforward. Curiously, anilines (such as dimethyaniline) failed completely under these conditions, instead affording only dark mixtures of numerous products from which the anticipated oxidation product could not be separated.

Table 3. Oxidation of carbamate 1 in 1-ethyl-3-methylimidazolium triflimide.

\begin{tabular}{ccccc}
\hline Entry & Volume\% MeOH & \% Yield of 2 & State of RTIL & Viscosity (cP) \\
\hline 1 & 5 & 0 & Black & 25 \\
2 & 10 & 4 & Dark orange & 16 \\
3 & 20 & 9 & Dark yellow & 10 \\
4 & 25 & 83 & Clear & 6 \\
$5^{\text {a }}$ & 33 & 89 & Pale yellow & \\
$6^{\text {b }}$ & 33 & 91 & Pale yellow & \\
$7^{\text {c }}$ & 33 & 93 & Pale yellow & \\
\hline
\end{tabular}

${ }^{\mathrm{a}}$ RTIL recycled from entry $4 ;{ }^{\mathrm{b}}$ RTIL recycled from entry $5 ;{ }^{\mathrm{c}}$ RTIL recycled from entry 6.

Table 4. Oxidation of various carbamates in 1-ethyl-3-methylimidazolium triflimide.

\begin{tabular}{ccc}
\hline Entry & Carbamate & \% Yield of Methoxylated Product \\
\hline 1 & & 95 \\
2 & & \\
3 & & \\
&
\end{tabular}

\section{Experimental}

All reagents and solvents were used as received. An Epsilon system from BAS was employed for all CV experiments. A standard power supply used for gel electrophoresis from VWR was employed for all Shono oxidation experiments. A Bruker NMR spectrometer $\left(360 \mathrm{MHz}\right.$ at $\left.{ }^{1} \mathrm{H}\right)$ was used to collect all NMR spectra. 


\subsection{Decyltributylammonium Tosylate}

\subsubsection{Decyl Tosylate}

In a round-bottom flask, $33.8 \mathrm{~g}(0.214 \mathrm{~mol})$ of decyl alcohol was added to pyridine $(100 \mathrm{~mL})$ and allowed to stir for a few minutes. Tosyl chloride (48.85 g, $0.257 \mathrm{~mol})$ was slowly added while the flask was cooled in an ice water bath. The solution was allowed to stir under nitrogen for $3 \mathrm{~h}$. The product was diluted with hexanes $(800 \mathrm{~mL})$ and passed through a small plug of silica (30\% ethyl acetate in hexane). The resulting solution was then washed three times with $\mathrm{HCl}(1 \mathrm{~N}, 200 \mathrm{~mL})$ and once with distilled water $(200 \mathrm{~mL})$. The organic layer was dried with $\mathrm{MgSO}_{4}$, and the remaining solvent was removed under reduced pressure to afford $52.3 \mathrm{~g}$ of decyl tosylate (yield $84 \%$ ). ${ }^{1} \mathrm{H}-\mathrm{NMR}$ (360 $\mathrm{MHz}$, $\left.\mathrm{CDCl}_{3}\right): \delta 7.77(\mathrm{~d}, 2 \mathrm{H}, J=10.8), 7.32(\mathrm{~d}, 2 \mathrm{H}, J=7.2 \mathrm{~Hz}), 3.98(\mathrm{t}, 2 \mathrm{H}, J=3.9 \mathrm{~Hz}), 2.43(\mathrm{~s}, 3 \mathrm{H}), 1.64$ $(\mathrm{m}, 2 \mathrm{H}), 1.23(\mathrm{~m}, 14 \mathrm{H}), 0.086(\mathrm{t}, 3 \mathrm{H}, J=7.92 \mathrm{~Hz})$.

\subsubsection{Decyltributylammonium tosylate}

Decyl tosylate $(47.44 \mathrm{~g}, 0.152 \mathrm{~mol})$ was dissolved in ethanol $(50 \mathrm{~mL})$ in a round-bottom flask. To this was added of tributylamine $(38.11 \mathrm{~mL}, 0.16 \mathrm{~mol})$ with stirring. The solution slowly brought to 75-80 ${ }^{\circ} \mathrm{C}$ and heated overnight. The ethanol was removed under reduced pressure, and the salt was washed three times with hexanes. The residual hexanes was removed at reduced pressure, and the product was dried overnight under vacuum at $70{ }^{\circ} \mathrm{C}$ to produce $72 \mathrm{~g}(88 \%)$ of DTAT as a pale yellow very viscous liquid, which solidifies over the period of several days. ${ }^{1} \mathrm{H}-\mathrm{NMR}\left(360 \mathrm{MHz}, \mathrm{CDCl}_{3}\right)$ : $\delta 7.60(\mathrm{~d}, 2 \mathrm{H}, J=9.72 \mathrm{~Hz}), 6.98(\mathrm{~d}, 2 \mathrm{H}, J=10.8 \mathrm{~Hz}), 3.00(\mathrm{~m}, 6 \mathrm{H}), 2.83(\mathrm{~m}, 2 \mathrm{H}), 2.19(\mathrm{~s}, 3 \mathrm{H}), 1.48$ $(\mathrm{m}, 6 \mathrm{H}), 1.36(\mathrm{~m}, 2 \mathrm{H}), 1.15(\mathrm{~m}, 18 \mathrm{H}), 0.75(\mathrm{~m}, 14 \mathrm{H}) .{ }^{13} \mathrm{C}-\mathrm{NMR}:\left(90 \mathrm{MHz}, \mathrm{CDCl}_{3}\right) \delta 142.0,140.6$, $130.1,129.3,60.3,60.1,31.9,29.6,29.5,29.4,29.1,29.0,24.5,24.3,22.7,21.3,21.2,14.1,13.9$.

\subsubsection{Decyltributylammonium bis(trifluoromethanesulfonyl)imide}

In a round-bottom flask, tributylamine $(37 \mathrm{~g}, 0.20 \mathrm{~mol})$ was stirred with acetonitrile $(47 \mathrm{~mL})$. Bromodecane ( $44.2 \mathrm{~g}, 0.20 \mathrm{~mol}$ ) was then added dropwise to this solution. The mixture was stirred at $70{ }^{\circ} \mathrm{C}$ for $48 \mathrm{~h}$ after which the solvent was removed under reduced pressure. The product was washed three times with hexanes and then dried over night under reduced pressure to afford $69.02 \mathrm{~g}(85 \%)$ decyltributylammonium bromide, as an orange viscous liquid. Decyltributylammonium bromide $(47.81 \mathrm{~g}, 0.118 \mathrm{~mol})$ was dissolved in distilled water $(154 \mathrm{~mL})$. Separately lithium bis(trifluoromethanesulfonyl)imide $(34.2 \mathrm{~g}, 0.120 \mathrm{~mol})$ was dissolved in distilled water $(25 \mathrm{~g})$. The two aqueous solutions were mixed together and then stirred at room temperature for at least three hours. The product (organic phase) was separated from the aqueous phase and was washed with distilled water three times to remove any water-soluble impurities. The product was then stirred with activated charcoal and filtered with neutral alumina. The final product was dried overnight under vacuum at $70{ }^{\circ} \mathrm{C}$ to afford $64 \mathrm{~g}(92 \%)$ of the product as a pale orange viscous liquid. The product was determined to be halide-free via the method described by Seddon [42]. ${ }^{1} \mathrm{H}-\mathrm{NMR}\left(360 \mathrm{MHz}, \mathrm{CDCl}_{3}\right): \delta 3.15(\mathrm{~m}, 8 \mathrm{H})$, $1.59(\mathrm{~m}, 8 \mathrm{H}), 1.31(\mathrm{~m}, 18 \mathrm{H}), 0.935(\mathrm{~m}, 14 \mathrm{H}) .{ }^{13} \mathrm{C}-\mathrm{NMR}\left(90 \mathrm{MHz}, \mathrm{CDCl}_{3}\right) \delta 137.2(\mathrm{q}, J=278 \mathrm{~Hz})$, $60.4,60.0,31.8,29.8,29.6,29.5,29.1,29.0,24.4,22.6,21.3,21.1,14.0,13.9$. 


\subsubsection{1-Ethyl-3-Methylimidazolium bis(trifluoromethanesulfonyl)imide [43]}

To a round-bottom flask were added 1-methylimidazole $(38.84 \mathrm{~mL}, 0.488 \mathrm{~mol})$ and ethylbromide $(36.00 \mathrm{~mL}, 0.488 \mathrm{~mol})$. The solution was stirred at $75-85^{\circ} \mathrm{C}$ for $72 \mathrm{~h}$. The product was washed three times with ethyl acetate. The residual ethyl acetate was removed at reduced pressure to afford 1-ethyl-3-methylimidazolium bromide as a very hard, white solid. 1-Ethyl-3-methylimidazolium bromide (22.5 g, $0.118 \mathrm{~mol})$ was dissolved in distilled water (154 mL). Separately lithium bis-(trifluoromethanesulfonyl)imide $(34.2 \mathrm{~g}, 0.120 \mathrm{~mol})$ was dissolved in distilled water $(25 \mathrm{~g})$. The two aqueous solutions were mixed together and then stirred at room temperature for at least $3 \mathrm{~h}$. The product (the organic phase) was separated from the aqueous phase and was washed with distilled water three times to removed any water-soluble impurities. The product was then stirred with activated charcoal and filtered through neutral alumina. The final product was dried overnight under vacuum at $70{ }^{\circ} \mathrm{C}$ to afford and $41 \mathrm{~g}(88 \%)$ of the product as a colorless slightly viscous liquid. The product was determined to be halide-free via the method described by Seddon [42]. ${ }^{1} \mathrm{H}-\mathrm{NMR}\left(360 \mathrm{MHz}, \mathrm{CDCl}_{3}\right)$ : $\delta 8.82(\mathrm{~s}, 1 \mathrm{H}), 7.27(\mathrm{~d}, 2 \mathrm{H}, J=7.2 \mathrm{~Hz}), 4.25(\mathrm{q}, 2 \mathrm{H}, J=7.2 \mathrm{~Hz}), 3.95(\mathrm{~s}, 3 \mathrm{H}), 1.58(\mathrm{t}, 3 \mathrm{H}, J=7.2 \mathrm{~Hz})$.

\subsection{General Procedure for Preparing Carbamates}

$N$-Carboethoxypyrrolidine

In a dry round-bottom flask $\mathrm{CH}_{2} \mathrm{Cl}_{2}(100 \mathrm{~mL})$ was added to an equal volume of saturated aqueous sodium bicarbonate. Pyrrolidine $(7.1 \mathrm{~g}, 0.100 \mathrm{~mol})$ was added to the flask and allowed to stir in an ice bath. To this mixture, ethyl chloroformate $(11.4 \mathrm{~g}, 0.105 \mathrm{~mol})$ was added slowly while watching for heat evolution. The reaction was allowed to stir for $4 \mathrm{~h}$ after which the product (organic phase) was separated from the aqueous phase and was washed with distilled water three times to remove any water-soluble impurities. The organic layer was then dried with magnesium sulfate, filtered, and the solvent was removed in vacuo to afford $13.7 \mathrm{~g}$ (97\%) of the carbamate as a colorless liquid with spectral properties consistent with those reported in the literature [41]. ${ }^{1} \mathrm{H}-\mathrm{NMR}\left(360 \mathrm{MHz}, \mathrm{CDCl}_{3}\right): \delta$ 4.02 (q, 2H, $J=7.2 \mathrm{~Hz}), 3.24(\mathrm{~m}, 4 \mathrm{H}), 1.74(\mathrm{~m}, 4 \mathrm{H}), 1.14(\mathrm{t}, 3 \mathrm{H}, J=7.2 \mathrm{~Hz})$. All carbamates were prepared according to this general method using the corresponding amines.

N-Carboethoxypiperidine [44]. ${ }^{1} \mathrm{H}-\mathrm{NMR}\left(360 \mathrm{MHz}, \mathrm{CDCl}_{3}\right): \delta 4.03$ (q, 2H, J=7.2 Hz), 3.32 (t, 4H, $J=7.2 \mathrm{~Hz}), 1.46(\mathrm{~m}, 6 \mathrm{H}), 1.17$ (t, 3H, $J=7.2 \mathrm{~Hz})$.

N-Carboethoxymorpholine [41]. ${ }^{1} \mathrm{H}-\mathrm{NMR}:\left(360 \mathrm{MHz}, \mathrm{CDCl}_{3}\right) \delta 4.01$ (q, 2H, $\left.J=7.2 \mathrm{~Hz}\right), 3.514$ (t, 4H, $J=5.04 \mathrm{~Hz}), 3.33(\mathrm{t}, 4 \mathrm{H}, J=5.04 \mathrm{~Hz}), 1.132$ (t, 3H, $J=7.2 \mathrm{~Hz})$.

\subsection{Electrochemical Oxidation of $\mathrm{N}$-Carboethoxypyrrolidine}

The Control [45]

Into a $20 \mathrm{~mL}$ undivided cell fitted with a glassy carbon anode (the anode dimensions were $2.4 \mathrm{~cm} \times 2.4 \mathrm{~cm}$ though only $1 \mathrm{~cm}^{2}$ was submerged in the reaction solution) and a platinum wire cathode $(2 \mathrm{~mm}$ diameter $)$ were placed $N$-carboethoxypyrrolidine $(2.00 \mathrm{~g}, 0.014 \mathrm{~mol})$ and 
tetraethylammonium $p$-toluenesulfonate (Et ${ }_{4} \mathrm{NOTs}, 0.11739 \mathrm{~g}, 0.00039 \mathrm{~mol}$ ) as electrolyte and methanol $(12 \mathrm{~mL})$ as the solvent. While being stirred with argon bubbling, a constant current of $0.240 \mathrm{~A}$ was passed through the cell, which was externally cooled with water. After $2.34 \mathrm{~F} / \mathrm{mol}$ of electricity was passed (214 min), the solvent was removed in vacuo, and the product was separated from the electrolyte via distillation to afford the product in $82 \%$ with spectral properties consistent with those reported in the literature. ${ }^{1} \mathrm{H}-\mathrm{NMR}\left(360 \mathrm{MHz}, \mathrm{CDCl}_{3}\right): \delta 5.07(\mathrm{~m}, 1 \mathrm{H}), 3.93(\mathrm{q}, 2 \mathrm{H}, J=7.2 \mathrm{~Hz}), 3.26$ (s, 3H), $3.17(\mathrm{~m}, 2 \mathrm{H}), 1.78(\mathrm{~m}, 4 \mathrm{H}), 1.18(\mathrm{t}, 3 \mathrm{H}, J=7.2 \mathrm{~Hz})$.

\subsection{Using Ionic Liquid as Solvent/Electrolyte}

Into a $20 \mathrm{~mL}$ undivided cell fitted with a glassy carbon anode (the anode dimensions where $2.4 \mathrm{~cm} \times 2.4 \mathrm{~cm}$ though only $1 \mathrm{~cm}^{2}$ was submerged in the reaction solution) and a platinum plate cathode (the cathode dimensions where $2.48 \mathrm{~cm} \times 2.45 \mathrm{~cm}$ though only $1 \mathrm{~cm}^{2}$ was submerged in the reaction solution) were placed $N$-carboethoxypyrrolidine $(0.70 \mathrm{~g}, 0.005 \mathrm{~mol})$ and a solution of EMIM $\mathrm{NTf}_{2}(2.6 \mathrm{~mL})$ with methanol $(0.8 \mathrm{~mL})$ as the solvent/electrolyte. While being stirred with argon bubbling, a constant current of $5 \mathrm{~mA}$ was passed through the cell, which was externally cooled with water. After $800 \mathrm{~min}$, the methanol was removed under reduced pressure and the product was separated from EMIM $\mathrm{NTf}_{2}$ via distillation to afford the product in $89 \%$ yield along with recovered starting material. The current efficiency was $2.35 \mathrm{~F} / \mathrm{mol}$. The salt was then prepared for recycling by heating, at reduced pressure, to $100{ }^{\circ} \mathrm{C}$ for $2 \mathrm{~h}$ to remove any residual solvent or water absorbed from the air.

1-Methoxy-N-carboethoxypiperidine. This same procedure was repeated with recycled salt using $\mathrm{N}$-carboethoxy piperidine to afford the methoxylated product in $95 \%$ yield with a $2.62 \mathrm{~F} / \mathrm{mol}$ efficiency with spectra consistent with those reported in the literature [46]. ${ }^{1} \mathrm{H}-\mathrm{NMR}(360 \mathrm{MHz}$, $\left.\mathrm{CDCl}_{3}\right): \delta 5.30(\mathrm{~m}, 1 \mathrm{H}), 4.16(\mathrm{q}, 2 \mathrm{H}, J=7.2 \mathrm{~Hz}), 3.37(\mathrm{~s}, 3 \mathrm{H}), 3.26(\mathrm{~m}, 2 \mathrm{H}), 1.98(\mathrm{~m}, 2 \mathrm{H}), 1.54$ $(\mathrm{m}, 4 \mathrm{H}), 1.31(\mathrm{t}, 3 \mathrm{H}, J=7.2 \mathrm{~Hz})$.

1-Methoxy-N-carboethoxypiperidine. This same procedure was repeated with recycled salt using $\mathrm{N}$-carboethoxy morpholine to afford the methoxylated product in $81 \%$ yield with a $3.05 \mathrm{~F} / \mathrm{mol}$ efficiency with spectra consistent with those reported in the literature [47]. ${ }^{1} \mathrm{H}-\mathrm{NMR}(360 \mathrm{MHz}$, $\left.\mathrm{CDCl}_{3}\right): \delta 5.10(\mathrm{~m}, 1 \mathrm{H}), 4.18(\mathrm{q}, 2 \mathrm{H}, J=7.2 \mathrm{~Hz}), 3.85(\mathrm{~s}, 3 \mathrm{H}), 3.80(\mathrm{~m}, 2 \mathrm{H}), 3.50(\mathrm{~m}, 2 \mathrm{H}), 3.3$ $(\mathrm{m}, 2 \mathrm{H}), 1.25(\mathrm{t}, 3 \mathrm{H}, J=7.2 \mathrm{~Hz})$.

\subsection{Viscosity Measurements}

All viscosities were determined using a Brookfield DVE viscometer. Reported values are the average of three measurements. Note that no temperature control module was available, so the temperature of the samples did vary slightly from between 20 and $22^{\circ} \mathrm{C}$.

\section{Conclusions}

During this course of this research, it became quite apparent that the high viscosity of ionic liquids is a definite problem for electrosynthesis. This feature has not been observed in most of the previous studies, because they were conducted under controlled potential conditions. Indeed, in one of the 
previous reports employing constant current conditions (as was done in the present study), Barhdadi and co-workers obtained poor results unless a co-solvent (DMF in their case) was employed to decrease the viscosity of the reaction medium [34]. What we suspect is happening is that the higher viscosity of the ionic liquid slows the rate of diffusion of the starting material to and from the electrode surface. Since the Shono oxidation occurs at or very near the electrode surface, the slowed diffusion results in a situation in which there is not enough starting material present to react with the current that is being generated. As a result, the next most easily oxidized species will react, thus leading first to over oxidation product 3 and then to oxidation of the ionic liquid.

This over oxidation problem can be limited by the use of VOC co-solvents, but that, obviously, reduces the value (in terms of being environmentally friendly) of using ionic liquids. The other option is to employ even less viscous ionic liquids. Although there is continuing improvement in this area, there is still a clear need for even less viscous ionic liquids ( $<10 \mathrm{cP}$ based upon our observations) that still maintain a wide electrochemical window before their full potential in electrochemistry can be unleashed.

\section{Conflict of Interest}

The authors declare no conflict of interest.

\section{References and Notes}

1. Wilkes, J.S. A short history of ionic liquids - From molten salts to neoteric solvents. Green Chem. 2002, 10, 73-80.

2. Hallett, J.P.; Welton, T. Room-temperature ionic liquids: Solvents for synthesis and catalysis. Chem. Rev. 2011, 111, 3508-3576.

3. Wasserscheid, P.; Welton, T. Ionic Liquids in Synthesis, 2nd ed.; Wiley-VCH: Weinheim, Germany, 2008.

4. Handy, S.T. Room temperature ionic liquids: Different classes and physical properties. Curr. Org. Chem. 2005, 9, 959-988.

5. Wasserscheid, P.; Keim, W. Ionic liquids-New "solutions" for transition metal catalysis. Angew. Chem. Int. Ed. 2000, 39, 3772-3789.

6. Parvulescu, V.I.; Hardacre, C. Catalysis in ionic liquids. 2007, 107, 2615-2665.

7. Ennis, E.; Handy, S.T. A facile route to C2-substituted imidazolium ionic liquids. Molecules 2009, 14, 2235-2245.

8. Handy, S.T. One-pot halogenation-Heck coupling reactions in ionic liquids. Synlett 2006, 3176-3178.

9. Handy, S.T.; Okello, M. The 2-position of imidazolium ionic liquids: Substitution and exchange. J. Org. Chem. 2005, 70, 1915-1918.

10. Handy, S.T.; Okello, M. Fructose-derived ionic liquids: Recyclable homogeneous supports. Tetrahedron Lett. 2003, 44, 8399-8402.

11. Handy, S.T. Greener solvents: Room temperature ionic liquids from biorenewable sources. Chem. Eur. J. 2003, 9, 2938-2944.

12. Handy, S.T.; Okello, M.; Dickenson, G. Solvents from biorenewable sources: Ionic liquids based on fructose. Org. Lett. 2003, 5, 2513-2515. 
13. Frontana-Uribe, B.A.; Little, R.D.; Ibanez, J.G.; Palma, A.; Vasquez-Medrano, R. Organic electrosynthesis: A promising green methodology in organic chemistry. Green Chem. 2010, 12, 2099-2119.

14. Hapiot, P.; Lagrost, C. Electrochemical reactivity in room-temperature ionic liquids. Chem. Rev. 2008, 108, 2238-2264.

15. Martiz, B.; Keyrouz, R.; Gmouh, S.; Vaultier, M.; Jouikov, V. Superoxide-stable ionic liquids: New and efficient media for electrosynthesis of functional siloxanes. Chem. Commun. 2004, 674-675.

16. Damlin, P.; Kvarnström, C.; Ivaska, A. Electrochemical synthesis and in situ spectoelectrochemical characterization of poly(3,4-ethylenedioxythhiophene) (PEDOT) in room temperature ionic liquids. J. Electroanal. Chem. 2004, 570, 113-122.

17. Sekiguchi, K.; Atobe, M.; Fuchigami, T. Electrooxidative polymerization of aromatic compounds in 1-ethyl-3-methylimidazolium trifluoromethanesulfonate room-temperature ionic liquid. J. Electroanal. Chem. 2003, 557, 1-7.

18. Shen, Y.; Atobe, M.; Fuchigami, T. Electroorganic synthesis using a fluoride ion mediator under ultrasonic irradiation: Synthesis of oxindole and 3-oxotetrahydroisoquinoline derivatives. Org. Lett. 2004, 6, 2441-2444.

19. Sawamura, T.; Inagi, S.; Fuchigami, T. Anodic fluorination and fluorodesulfurization in ionic liquid hydrogen fluoride salts with polyether additives. J. Electrochem. Soc. 2009, E26-E28.

20. Hasegawa, M.; Ishii, H.; Cao, Y.; Fuchigami, T. Regioselective anodic monofluorination of ethers, lactones, carbonates, and esters using ionic liquid fluoride salts. J. Electrochem. Soc. 2006, D162-D166.

21. Hasegawa, M.; Ishii, H.; Fuchigami, T. Selective anodic fluorination of phthalides in ionic liquids. Green Chem. 2003, 5, 512-515.

22. Hasegawa, M. Ishii, H. Fuchigami, T. Electroorganic synthesis under solvent-free conditions. Highly regioselective anodic monofluorination of cyclic ethers, lactones, and a cyclic carbonate. Tetrahedron Lett. 2002, 43, 1503-1505.

23. Hasegawa, M.; Fuchigami, T. Electroorganic reactions in ionic liquids $5\{1\}$. Anodic fluorodesulfurization of phthalide, ethylene carbonate, and glucopyranosides having arylthio groups. Electrochim. Acta 2004, 49, 3367-3372.

24. Barhdadi, R.; Comminges, C.; Doherty, A.P.; Nédélee, J.Y.; O’Toole, S.; Troupel, M. The electrochemistry of TEMPO-mediated oxidation of alcohols in ionic liquid. J. Appl. Electrochem. 2007, 37, 723-728.

25. Herath, A.C.; Becker, J.Y. 2,2,6,6-Tetramethylpiperidine-1-oxyl (TEMPO)-mediated catalytic oxidation of benzyl alcohol in acetonitrile and ionic liquid 1-buthyl-3-methyl-imidazolium hexafluorophosphate [BMIM][PF 6$]$ : Kinetic analysis. Electrochim. Acta 2008, 53, 4324-4330.

26. Ho, K.-P.; Wong, K.-Y.; Chan, T.H. Indirect catalytic epoxidation with hydrogen peroxide electrogenerated in ionic liquids. Tetrahedron 2006, 62, 6650-6658.

27. Tang, M.C.-Y.; Wong, K.-Y.; Chan, T.H. Electrosynthesis of hydrogen peroxide in room temperature ionic liquids and in situ epoxidation of alkenes. Chem. Commun. 2005, 1345-1347.

28. Gaillon, L.; Bedioui, F. First example of electroassisted biomimetic activation of molecular oxygen by a (salen)Mn epoxidation catalyst in a room-temperature ionic liquid. Chem. Commun. 2001, 1458-1459. 
29. Lagrost, C.; Hapiot, P.; Vaultier, M. The influence of room-temperature ionic liquids on the stereoselectivity and kinetics of the electrochemical pinacol coupling of acetophenone. Green Chem. 2005, 7, 468-474.

30. Villagrán, C.; Banks, C.; Pitner, W.; Hardacre, C.; Compton, R.G. Electroreduction of $\mathrm{N}$-methylphthalimide in room temperature ionic liquids under insonated and silent conditions. Ultrasonics Sonochemistry 2005, 12, 423-428.

31. Mellah, M.; Zeitouny, J.; Gmouh, S.; Vaultier, M.; Jouikov, V. Oxidative self-coupling of aromatic compounds in ionic liquids. Electrochem. Commun. 2005, 7, 869-874.

32. Mellah, M.; Gmouh, M.; Vaultier, M.; Jouikov, V. Electrocatalytic dimerisation of $\mathrm{PhBr}$ and $\mathrm{PhCH}_{2} \mathrm{Br}$ in [BMIM] ${ }^{+} \mathrm{NTf}_{2}^{-}$ionic liquid. Electrochem. Commun. 2005, 5, 591-593.

33. Sweeny, B.K.; Peters, D.G. Cyclic Voltametric study of the catalytic behavior of nickel(I) salen electrogenerated at a glassy carbon electrode in an ionic liquid (1-butyl-3-methylimidazolium tetrafluoroborate, $\mathrm{BMIM}^{+} \mathrm{BF}_{4}{ }^{-}$). Electrochem. Commun. 2001, 3, 712-715.

34. Barhdadi, R.; Courtinard, C.; Nédélee, J.Y.; Troupel, M. Room-temperature ionic liquids as new solvents for organic electrosynthesis. The first examples of direct or nickel-catalysed electroreductive coupling involving organic halides. Chem. Commun. 2003, 1434-1435.

35. Jabbar, M.A.; Shimakoshi, H.; Hisaeda, Y. Enhanced reactivity of hydrophobic vitamin $B_{12}$ towards the dechlorination of DDT in ionic liquid. Chem. Commun. 2007, 1653-1655.

36. Feroci, M.; Chiarotto, I.; Orsini, M.; Sotgiu, G.; Inesi, A. Reactivity of electrogenerated $\mathrm{N}$-heterocyclic carbenes in room-temperature ionic liquids. Cyclization to 2-azetidinone ring via C-3/C-4 bond formation. Adv. Synth. Catal. 2008, 350, 1355-1359.

37. Yang, H.; Gu, Y.; Deng, Y.; Shi, F. Electrochemical activation of carbon dioxide in ionic liquid: synthesis of cyclic carbonates at mild reaction conditions. Chem. Commun. 2002, 274-275.

38. Zhang, L.; Niu, D.; Zhang, K.; Zhang, G.; Luo, Y.; Lu, J. Electrochemical activation of $\mathrm{CO}_{2}$ in ionic liquid $\left(\mathrm{BMIMBF}_{4}\right)$ : Synthesis of organic carbonates under mild conditions. Green Chem. 2008, 10, 202-206.

39. Chiarotto, I.; Feeney, M.M.M.; Feroci, M.; Inesi, A. Electrogenerated $N$-heterocyclic carbene: $\mathrm{N}$-Acylation of chiral oxaolidin-2-ones in ionic liquids. Electrochim. Acta 2009, 54, 1638-1644.

40. Chiarotto, I.; Feroci, M.; Feeney, M.M.M.; Inesi, A. Study on the reactivity of aldehydes in electrolyzed ionic liquids: Benzoin Condensation-Volatile Organic Compounds (VOCs) vs. Room Temperature Ionic Liquids (RTILs). Adv. Synth. Catal. 2010, 352, 3287-3292.

41. Kita, Y.; Haruta, J.; Tagawa, H.; Tamura, Y. Facile and efficient carboalkoxylation and carboaryloxylation of amines. J. Org. Chem. 1980, 45, 4519-4522.

42. Seddon, K.R.; Stark, A.; Torres, M.-J. Influence of chloride, water, and organic solvents on the physical properties of ionic liquids. Pure Appl. Chem. 2000, 72, 2275-2287.

43. Chu, Y.; Deng, H.; Cheng, J.-P. An Acidity Scale of 1,3-Dialkylimidazolium Salts in Dimethyl Sulfoxide Solution. J. Org. Chem. 2007, 72, 7790-7793.

44. Ballini, R.; Fiorini, D.; Maggi, R.; Righi, P.; Sartori, G.; Sartorio, R. TBD-catalyzed solventless synthesis of symmetrically N,N'-substituted ureas from primary amines and diethyl carbonate. Green Chem. 2003, 5, 396-398. 
45. Shono, T.; Matsumura, Y.; Tsubata, K. Electroorganic chemistry. 46. A new carbon-carbon bond forming reaction at the $\alpha$-position of amines utilizing anodic oxidation as a key step. $J$. Am. Chem. Soc. 1981, 103, 1172-1176.

46. Torii, S.; Inokuchi, T.; Akahosi, F.; Kubota, M. Facile access to 6-methoxy-1,2,3,6-tetrahydroand 4-hydroxy-1,2,3,4-tetrahydropyridines by electrochemical haloalkoxylation-dehydrohalogenation sequence as a key operation. Synthesis 1987, 3, 242-245.

47. Nishitani, T.; Horikawa, H.; Iwasaki, T.; Matsumoto, K.; Inoue, I.; Miyoshi, M. Synthetic electroorganic chemistry. 14. Synthesis of 5-fluorouracil derivatives having $N$-acylazacycloalkanes and lactams. J. Org. Chem. 1982, 47, 1706-1712.

Sample Availability: Not available.

(C) 2011 by the authors; licensee MDPI, Basel, Switzerland. This article is an open access article distributed under the terms and conditions of the Creative Commons Attribution license (http://creativecommons.org/licenses/by/3.0/). 